\title{
Numerical Analysis for Effective Transplant and Seabed Restoration for Recovery of Pen shell Resources in the Ariake Sea, Japan
}

\author{
T. Tabata, K. Hiramatsu, and M. Harada
}

\begin{abstract}
Numerical simulation was conducted in order to support the recovery of pen shell Atrina pectinata resources in the Ariake Sea, Japan. Larval transport model was used to predict migration of larvae drifting on tidal currents which were calculated using a two-dimensional depth-averaged model. 14 release points were defined as potential new spawning grounds for the pen shell. The number of larvae that migrated from these points to habitable areas for pen shells (depth: $2<\boldsymbol{h}$ $<20 \mathrm{~m}$, grain size median diameter: $>62.5 \mu \mathrm{m}$ ) was calculated for each release point. Consequently, larvae released from the northeast area (particularly from Point 13, Noku 210) reached the largest habitable area. In addition, most of the larvae ultimately drifted to Isahaya Bay, suggesting that transplanting pen shell in the northeast area and seabed restoration in Isahaya Bay would be the most effective approach to recovery of pen shell resources.
\end{abstract}

Index Terms-Larvae, particle tracking, hydrodynamic model, seabed environment, Ariake Sea, pen shell.

\section{INTRODUCTION}

The Ariake Sea is a typical semi-enclosed inner bay located near Kyushu Island, Japan (Fig. 1; area, 1,700 m² average depth, $20 \mathrm{~m}$; volume, 34 billion $\mathrm{m}^{3}$ ). The western portion of Isahaya Bay is closed off for tidal basin reclamation. Because of its unique geomorphic characteristics, the Ariake Sea has the largest tidal range in Japan, up to $6 \mathrm{~m}$. Therefore, the tidal range is so large that more than $200 \mathrm{~km}^{2}$ of tide flats emerge at the spring ebb tide in the Ariake Sea. Many rivers flow into the Ariake Sea (Fig. 1); its entire watershed is $8,420 \mathrm{~km}^{2}$ and the annual volume of freshwater inflow is about $8 \times 10^{9} \mathrm{~m}^{3}$. Vast quantities of nutrients flow into the sea and its retention period is very long because of its geomorphic characteristics. Hence, the Ariake Sea is a homeostatic eutrophic sea. Generally, red tide and anoxic water mass are easily induced in those areas, and these can have negative impacts. However, owing to the unique environmental features of the Ariake Sea, such as high tide and the presence of floating mud, this region did not

Manuscript received April 15, 2014; revised June 9, 2014. This research was partially supported by a project of habitat investigation of principal fish and shellfish in the Ariake Sea in 2011 (Kyushu Regional Agricultural Administration Office), the FY2012-2014 JSPS Core-to-Core Program (B. Asia-Africa Science Platforms) and a JSPS KAKENHI Grant Number 23380144, 241526.

T. Tabata is with the Department of Agro-Environmental Sciences, Graduate School of Bioresource and Bioenvironmental Sciences, Kyushu University, Japan (e-mail: t.tabata.1232@gmail.com).

K. Hiramatsu and M. Harada are with the Department of Agro-Environmental Sciences, Faculty of Agriculture, Kyushu University (e-mail: hiramatsu@bpes.kyushu-u.ac.jp, mharada@bpes.kyushu-u.ac.jp). experience the negative impacts in past years; thus, the region had high bioproductivity. Therefore, a wide variety of characteristic fishing industries, such as nori aquafarming and shellfishery, have been active in the Ariake Sea for many years.

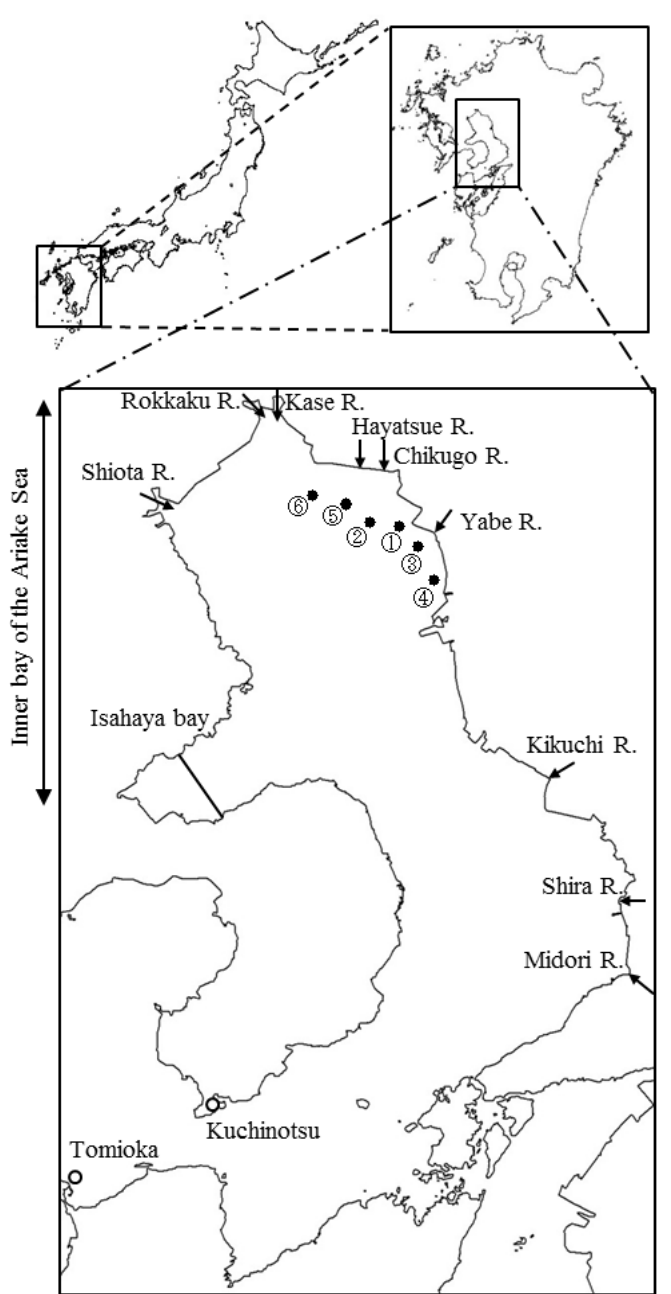

Fig. 1. Location of the Ariake Sea, river inflow, and the six observation stations for tidal currents.

The pen shell Atrina pectinata is a well-known bivalve harvested in the Ariake Sea. Its adductor muscle and mantle are marketable as edible shellfish. Pen shells adhere to the seabed point downward and have a triangular shell reaching about $40 \mathrm{~cm}$ in length. The nursery grounds of the pen shell are in the inner bay, with suitable water temperatures of 22.0-28.5 ${ }^{\circ} \mathrm{C}$. In the summer, pen shells spawn and the ova are fertilized in the water. After hatching, the fertilized ova become suspended larvae with a shell length of $150-585 \mu \mathrm{m}$ [1]. After a floating period of 30-40 days, the floating larvae 
become full-grown larvae, which then settle onto the bottom and transform into juvenile bivalves. The juvenile bivalves grow into adults in that location.

Production of pen shells in the Ariake Sea increased dramatically until the 1970s. However, environmental deterioration of the Ariake Sea has become a serious social problem. Since 1985, the number of red tide outbreaks has exceeded 20/year. During 1998-2002, red tides occurred >30 times/year. Numerous studies have been conducted of a large anoxic water mass, which has also become a serious issue in the Ariake Sea [2]-[4]. Pen shells have been affected by this environmental deterioration in the Ariake Sea. In 1979, the production was 29,305 tons. However, after that year, production substantially decreased. And the production was only 3,786 tons in 1996. Of additional concern, pen shell resources have significantly declined because of pen shell mortality [5], [6], attributed to the anoxic water mass and degradation of the quality of the seabed. Now, little pen shell has been observed in the Ariake Sea. Therefore, shellfishery of pen shell has been stopped. Hence, recovery of pen shell resources is one of the most urgent issues in the Ariake Sea.

For this study, we considered degradation of the quality of the seabed to be a potential cause of low harvest of pen shells. Reference [7] conducted an experiment on the effect of resuspended mud on pen shells and reported that deposits of resuspended mud caused critical damage to pen shells. Reference [8] surveyed the seabed environment and reported that a reduction in grain size was occurring in the northwest portion of the Ariake Sea, where mortality of pen shells has frequently occurred. Restoration of the seabed in the Ariake Sea will contribute to recovery of pen shell resources. However, the area is so large that it would be impossible to conduct seabed restoration throughout the entire Ariake Sea. Thus, in this study, we used numerical simulation to predict the settling areas of pen shell larvae to identify effective areas for seabed restoration and transplanting pen shell for resource recovery in the Ariake Sea.

\section{MATERIAL AND METHODS}

\section{A. Hydrodynamic Model}

Several larval transport models have been published [9]-[11]. Those simulations are often implemented using a three-dimensional model to accurately reproduce the behavior of larvae. However, there is little biological knowledge of pen shell larvae behavior in the Ariake Sea. Therefore, to identify effective areas for seabed restoration for recovery of pen shell resources, average migration of larvae in the sea may be more useful. Moreover, as noted above, the Ariake Sea has a large area compared to its depth and thus, horizontal flow is far greater than vertical flow. Hence, a two-dimensional depth-averaged model as is often used for shallow waters (eg. [12]) was developed by integrating a three-dimensional continuity equation and using Reynolds-averaged Navier-Stokes equations assuming the Boussinesq approximation and hydrostatic pressure. The governing equations of the model, taking into account the fluid resistance of seaweed (Nori) aquafarming grounds, were as follows:

$$
\begin{gathered}
\frac{\partial \eta}{\partial t}+\frac{\partial}{\partial x}\{U(h+\eta)\}+\frac{\partial}{\partial y}\{V(h+\eta)\}=0 \\
\frac{\partial U}{\partial t}+U \frac{\partial U}{\partial x}+V \frac{\partial U}{\partial y} \\
=f V-g \frac{\partial \eta}{\partial x}+v_{\mathrm{h}}\left(\frac{\partial^{2} U}{\partial x^{2}}+\frac{\partial^{2} U}{\partial^{2} y}\right) \\
+\frac{1}{h+\eta}\left(\frac{\tau_{\mathrm{s} x}}{\rho}-\frac{\tau_{\mathrm{b} x}}{\rho}-\frac{\tau_{\mathrm{L} x} A_{\mathrm{net}}}{\rho}-\frac{D_{\mathrm{P} x} A_{\mathrm{pole}}}{\rho}\right) \\
\frac{\partial V}{\partial t}+U \frac{\partial V}{\partial x}+V \frac{\partial V}{\partial y} \\
=-f U-g \frac{\partial \eta}{\partial y}+v_{\mathrm{h}}\left(\frac{\partial^{2} V}{\partial x^{2}}+\frac{\partial^{2} V}{\partial^{2} y}\right) \\
+\frac{1}{h+\eta}\left(\frac{\tau_{\mathrm{s} y}}{\rho}-\frac{\tau_{\mathrm{b} y}}{\rho}-\frac{\tau_{\mathrm{L} y} A_{\mathrm{net}}}{\rho}-\frac{D_{\mathrm{P} y} A_{\mathrm{pole}}}{\rho}\right)
\end{gathered}
$$

where $\eta$ is the water level; $t$, time; $\rho$, the density of water; $h$, the water depth; $f$, the Coriolis parameter; $g$, the acceleration of gravity; $\tau_{\mathrm{s}}$, the surface shear stress; $\tau_{b}$, the bottom shear stress; $A_{\text {net }}$, the ratio of the area of Nori nets to the water surface area; $A_{\text {pole }}$, the number of Nori poles per unit sea area; $\tau_{L}$, the Nori net shear stress; $D_{P}$, the resistance stress attributed to Nori poles. Furthermore, $U$ and $V$ are the horizontal velocity components in the $x$ and $y$ directions, respectively, and $v_{h}$ is the coefficient of eddy viscosity. The Smagorinsky model [13] was introduced to determine $v_{h}$. The Smagorinsky model can be expressed as follows:

$$
v_{h}=\frac{1}{2} S_{m} A_{G}\left\{\left(\frac{\partial U}{\partial x}\right)^{2}+\frac{1}{2}\left(\frac{\partial V}{\partial x}+\frac{\partial U}{\partial y}\right)+\left(\frac{\partial V}{\partial y}\right)^{2}\right\}^{1 / 2}
$$

where $S_{m}$ is the Smagorinsky coefficient and $A_{\mathrm{G}}$ is the mesh area. The surface shear stress due to wind and the bottom shear stress were calculated using the following equations:

$$
\begin{aligned}
& \frac{\tau_{\mathrm{s}}}{\rho}=\frac{\rho_{\mathrm{a}}}{\rho} \gamma_{\mathrm{s}}^{2} W_{10}^{2} \\
& \frac{\tau_{\mathrm{b}}}{\rho}=\frac{g n^{2} W^{2}}{(h+\eta)^{1 / 3}}
\end{aligned}
$$

where $\rho_{\mathrm{a}}$ is the density of air; $\gamma_{\mathrm{s}}$, the frictional coefficient at the surface; $n$, Manning's roughness coefficient; and $W$, horizontal velocity. $W_{10}$ is the wind velocity $10 \mathrm{~m}$ above the sea surface.

Tidal current data in the inner bay of the Ariake Sea were collected in winter, when Nori aquafarming areas are widespread. Therefore, to validate the model, Nori net shear stress and Nori pole resistance stress should be considered. Nori is farmed by implanting the seaweed on nets spread over a large area of the sea surface. In the Ariake Sea, Nori nets are tied to poles attached to the sea floor. A basic unit of Nori aquafarming area is called a "koma," and consists of four or five lines of Nori net. Therefore, fluid resistance in Nori aquafarming areas is based on that of the Nori nets and poles. These components of resistance were calculated using the 
following equations:

$$
\begin{gathered}
\tau_{L}=\frac{1}{2} \rho C_{f} W^{2} \\
D_{P}=\frac{1}{2} \rho C_{d} d \Delta z W^{2}
\end{gathered}
$$

where $C_{f}$ is the resistance coefficient for Nori nets; $d$, the diameter of a Nori pole; $\Delta z$, the length of the pole under water; and $C_{d}$, the resistance coefficient for Nori poles. According to [14], the resistance coefficient for Nori nets varies with the length of the Nori leaves. However, the length of the Nori and the time to harvest vary from place to place during the cultivation period. Therefore, the average length of Nori leaves based on 5 individual observations at 19 points in Nori aquafarming areas was used to determine the resistance coefficient for Nori nets. The resistance coefficient for Nori poles was calculated as a function of the Reynolds number. However, in the larval transport model, these Nori aquafarming terms were eliminated, because Nori aquafarming is not present in the Ariake Sea in summer while the pen shells are spawning.

A leapfrog finite difference method was used for numerical solution of the governing equations. In this method, water level and velocity are calculated alternately in each time step $\Delta t$. Table I shows the values used for parameters in the model.

\begin{tabular}{cc}
\hline TABLE I: PARAMETER VALUES USED IN THE NUMERICAL SIMULATION \\
\hline \hline Parameter & Value \\
\hline$\Delta t(\mathrm{~s})$ & 2.0 \\
$\Delta x, \Delta y(\mathrm{~m})$ & 500 \\
$f(/ \mathrm{s})$ & $7.9 \times 10^{-5}$ \\
$\rho\left(\mathrm{kg} / \mathrm{m}^{3}\right)$ & 1000 \\
$S_{\mathrm{m}}$ & 0.2 \\
$\rho_{\mathrm{a}}(\mathrm{kg} / \mathrm{m} 3)$ & 1.293 \\
$\gamma \mathrm{s}$ & 0.0015 \\
$\mathrm{~g}(\mathrm{~m} / \mathrm{s} 2)$ & 9.8 \\
$n\left(\mathrm{~s} / \mathrm{m}^{1 / 3}\right)$ & 0.02 \\
$C_{\mathrm{f}}$ & 0.014 \\
$C_{\mathrm{d}}$ & 1.1 \\
$\delta t(\mathrm{~s})$ & 20.0 \\
\hline \hline
\end{tabular}

\section{B. Topographic Data and Boundary Conditions}

The 500-m mesh depth dataset $(\Delta x, \Delta y)$ was constructed using GIS software by combining several datasets with different resolutions obtained from the Fukuoka and the Saga Prefectural Governments and the Japan Oceanographic Data Center. Fig. 1 shows 10 rivers that were included as inflows in the numerical calculations. One-year average inflow rates for each river were used in the model. At the boundary between land and sea, a nonslip boundary was introduced for velocity calculations. A land mask function was utilized with the wet-and-dry method to represent the emergence of tide flats [15]. In this model, tidal variation at the entrance of the bay drove the calculations. The tidal cycle in the Ariake Sea is semidiurnal; its tidal variation was calculated using 6 tidal harmonic constants at Tomioka. Tidal observation data were collected by the Fukuoka Prefectural Government and Saga Prefectural Government at the 6 points shown in Fig. 1 for validation of the model.

\section{Validation of the Model}

Fig. 2 shows the calculated and observed tidal current variations from 9:00 on 28 November to 8:00 on 29 November 2008 at 1 -h intervals. The calculated tidal currents accurately reproduced the observed data. Fig. 3 shows the results of the model at 03:20 on 29 November 2008 (spring ebb tide). Gray areas in Fig. 3 represent tide flats. The average tide in the Ariake Sea was $0.0 \mathrm{~m}$. Comparing tide flat areas to the seabed topography, it was apparent that the model accurately duplicated the emergence of tide flats. These results demonstrate that the simulation model accurately reproduces tide flats and tidal currents in the Ariake Sea. Using this model, distribution of the floating larvae of the pen shell was tracked and effective areas for recovery of pen shell resources were investigated.

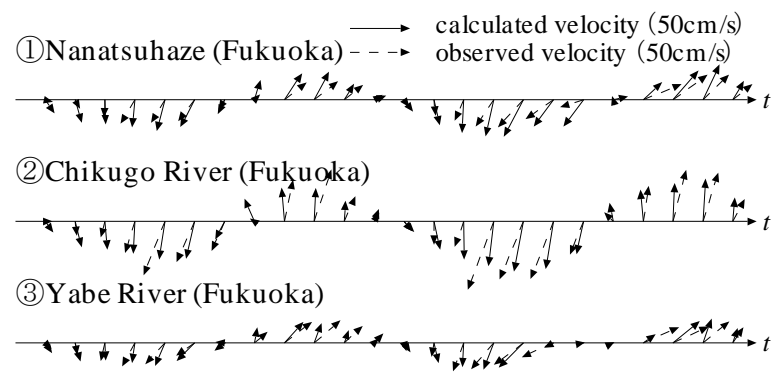

(4) Oomuta (Fukuoka)

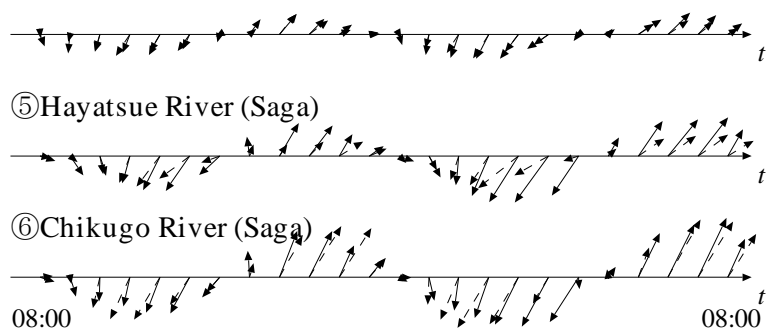

Fig. 2. Comparison of calculated and observed tidal currents from 9:00 on 28 November to 8:00 on 29 November 2008. Observers are indicated in parentheses after the names of the observation stations shown in Fig. 1.

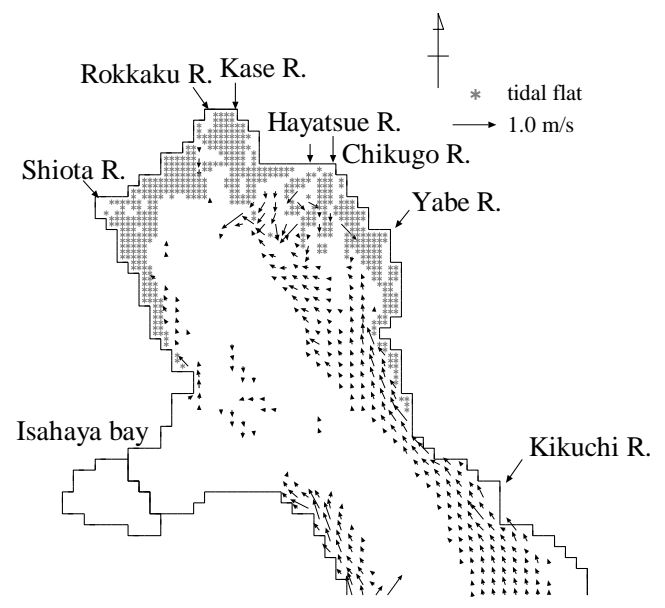

Fig. 3. Simulation results for tidal currents and emergence of tide flats calculated by the two-dimensional depth-averaged model for 03:20 on 29 November 2008 (spring ebb tide).

\section{Tracking Convective Dispersion of Pen Shell Larvae}

As described above, pen shell ova are fertilized in the water from July-September, the spawning season for pen shells. After hatching, the fertilized ova become suspended larvae, which absorb nutrients such as phytoplankton for 
30-40 days before settling on the bottom as full-grown larvae with shell length $>0.5 \mathrm{~mm}$. The full-grown larvae then become juvenile pen shells and remain where they have attached to the bottom. Pen shells can move around the bay only during the floating larvae period. Therefore, the nursery grounds of pen shells are determined by where the larvae settle. Moreover, [16], [17] have reported that pen shell larvae have no selectivity for appropriate seabed environments. Accordingly, if larvae do not settle in a habitable area, they cannot survive. Thus, the overall population of pen shells is dependent on the quality of the seabed environment. Therefore, the ability to predict pen shell larvae settlement areas would allow seabed restoration resources to be efficiently directed to locations where they will have the most beneficial effect.

A larval transport model that has frequently been used to track the behavior of particles in the sea (e.g., [18]-[20]) was utilized in this study. Pen shell larvae were defined as neutrally buoyant and modeled as passive particles floating on the tidal currents generated by the two-dimensional depth-averaged model. At time $n+1$, the position of a particle $\left(x^{(n+1)}, y^{(n+1)}\right)$ is determined from its position $\left(x^{(n)}, y^{(n)}\right)$ at time $\mathrm{n}$ using the following formulas:

$$
\begin{gathered}
x^{(n+1)}=x^{(n)}+U^{(n)} \delta t+\alpha \sqrt{2 D \delta t} \\
y^{(n+1)}=y^{(n)}+V^{(n)} \delta t+\beta \sqrt{2 D \delta t}
\end{gathered}
$$

where $\alpha$ and $\beta$ are normalized random numbers between 0 and $1, N(0,1) ; D$, the turbulent diffusion coefficient determined using the Smagorinsky model in (5); and $\Delta t$, the time step. According to [21], the limit of the ability of a larval shell to withstand drying is 3.5 hours. Hence, if a particle settled onto tide flats and remained there more than 3.5 hours, it was excluded from further calculations. By entering the release points and the floating period of the particles into the model, it is possible to estimate the areas in which pen shell larvae settle.

Fourteen points were selected as potential release points for particles (Fig. 4). Points 1-11 are locations where pen shells were observed in a previous survey; and Points 12-14 are the areas where the Fukuoka Prefectural Government is planning to conduct sand capping to create new spawning grounds for pen shells. At each release point, 10,000 particles were placed in the 500-m mesh evenly spaced apart. Then, using the larval transport model, the convective-dispersion behavior of the particles was analyzed.

The pen shell spawning period is July-September and its floating period is 30-40 days [1]. However, the relationship between the time of spawning and the tide is not clear. Therefore, to describe settlement of pen shell larvae, floating periods were established as follows: 1) from 14:00 on 10 August 2010 (spring ebb tide) to 14:00 on 9 September 2010 (spring ebb tide); 2) from 14:00 on 10 August 2010 (spring ebb tide) to 20:00 on 9 September 2010 (spring flood tide); 3 ) from 20:00 on 10 August 2010 (spring flood tide) to 14:00 on 9 September 2010 (spring ebb tide); and 4) from 20:00 on 10 August 2010 (spring flood tide) to 20:00 on 9 September 2010 (spring flood tide). The final settling areas of the pen shell larvae were predicted using the average of these 4 results.

As described above, pen shells have no selectivity for particular seabed environments. Thus, the growth rate of the pen shell after settlement depends on the appropriateness of the environment; the pen shell cannot grow if the settlement area is not suitable. Pen shells prefer a depth of 2-20 m and sand with a median diameter $(\mathrm{Md})>62.5 \mu \mathrm{m}$ [22], [23]. Hence, to evaluate the number of particles that settled in habitable areas, habitable regions in the Ariake Sea were determined based on grain size and bathymetry. [8] conducted a seabed survey comprising 91 locations in the Ariake Sea. The Md for each mesh square in the Ariake Sea was determined from these data by interpolation using inverse distance weighting. Fig. 4 shows the resulting habitable area for pen shells. Most of the habitable area is in the east, because the median grain size diameter in the western area is too small. Using these results, the number of particles that settled in habitable regions was calculated for each release point.

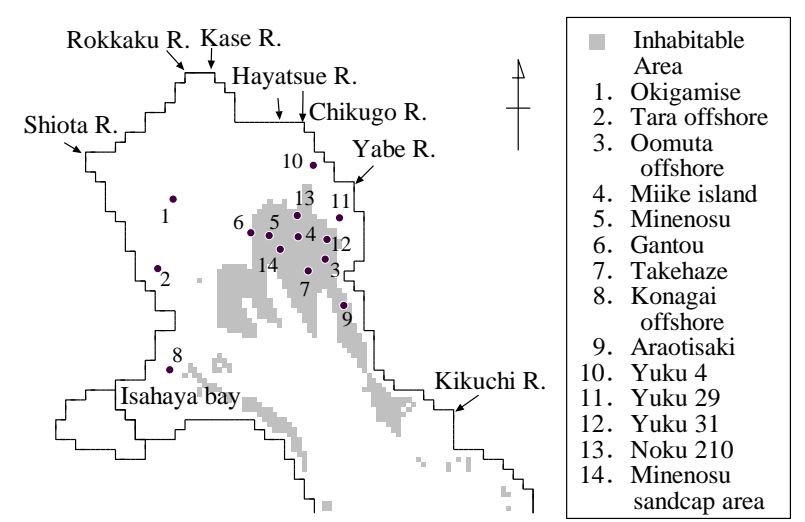

Fig. 4. Release points for 10,000 particles in the simulation. Points 1-11 are areas where pen shells were observed in a previous survey and Points 12-14 are areas where the Fukuoka Prefectural Government is considering conducting sand capping to create new spawning grounds. Also shown are habitable areas for pen shells deteremined based on grain size distribution and depth data sets (depth: $2<h<20 \mathrm{~m}$, median diameter: $>62.5 \mu \mathrm{m}$ ).

\section{Results}

TABLE II: THE NUMBER OF PARTICLES REACHING HABITABLE AREAS FROM EACH RELEASE POINT

\begin{tabular}{|c|c|c|}
\hline \multicolumn{2}{|c|}{ Release points } & Number of particles \\
\hline 1. & Okigamise & 492.7 \\
\hline 2. & Tara Offshore & 396.7 \\
\hline 3. & Oomuta Offshore & 1062.2 \\
\hline 4. & Miike Island & 1450.1 \\
\hline 5. & Minenosu & 1024.8 \\
\hline 6. & Gantou & 893.0 \\
\hline 7. & Takehaze & 1333.6 \\
\hline 8. & Konagai Offshore & 274.9 \\
\hline 9. & Araotisaki & 564.6 \\
\hline 10. & Yuku 4 & 393.3 \\
\hline 11. & Yuku 29 & 799.3 \\
\hline 12. & Yuku 31 & 977.8 \\
\hline 13. & Noku 210 & 1649.6 \\
\hline 14. & Minenosu Sandcap Area & 1015.4 \\
\hline
\end{tabular}

Table II shows the number of particles able to reach habitable areas from each release point. Fig. 5-Fig. 7 show the simulated distributions of larvae released from Points 13 (Noku 210), 1 (Okigamise), and 8 (Konagai offshore), 
respectively. Particles released from the northeast area of the Ariake Sea (Points 3-7 and 9-14) reached habitable areas in the greatest numbers (Table II). Not only did they reach habitable areas, but they were distributed over large areas of the inner bay of the Ariake Sea (Fig. 5). In contrast, particles released from the northwest area (Points 1 and 2) reached only the west side of the Ariake Sea (Fig. 6). Particles released from Isahaya Bay (Point 8) generally did not remain in the Ariake Sea, with most flowing out through the mouth (Fig. 7).

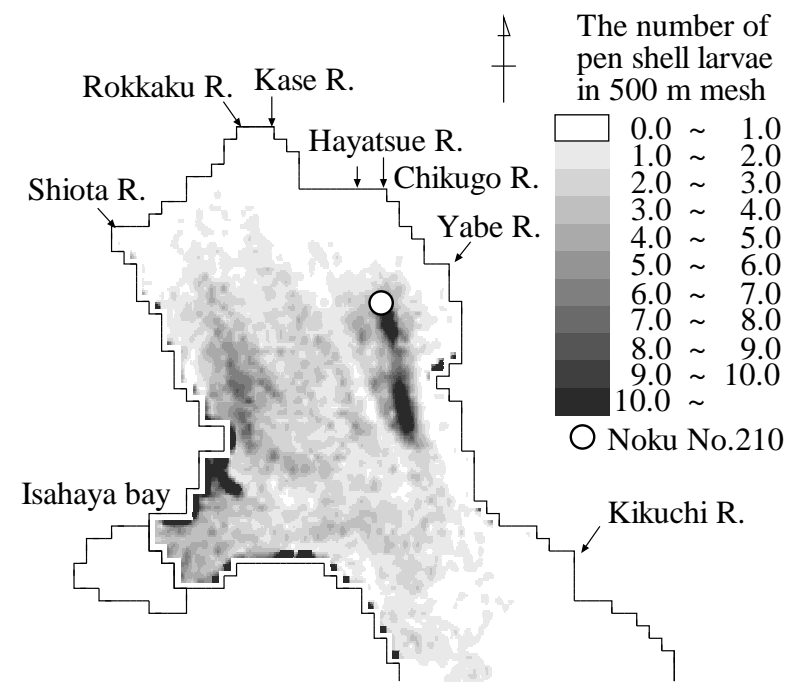

Fig. 5. Distribution of particles released from Point 13 (Noku No.210).

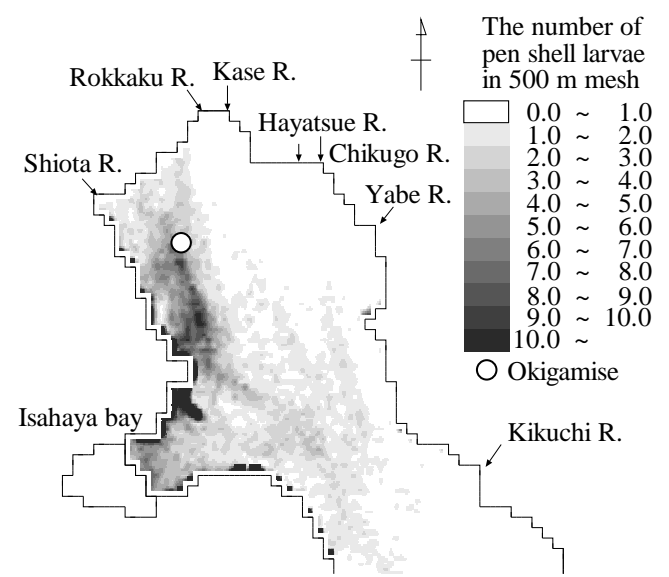

Fig. 6. Distribution of particles released from Point 1 (Okigamise).

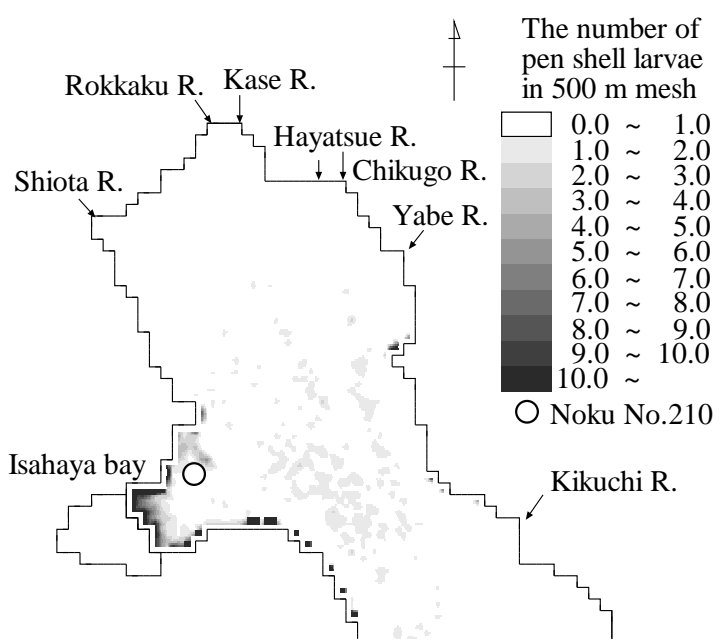

Fig. 7. Distribution of particles released from Point 8 (Konagai offshore).
The tidal residual flow in the inner bay of the Ariake Sea likely has a strong effect on these distributions. According to [24], tidal residual flow in the Ariake Sea circulates in an anticlockwise direction. Thus, tidal currents enter from the bay mouth and travel through the northeast, the northwest, Isahaya Bay, and back to the entrance. The results of the simulation agree with this report: the particles released from the northeast area spread over the entire area, those released from the northwest area reached only the western area, and those released from Isahaya Bay largely flowed out of the Ariake Sea through its mouth.

\section{DISCUSSION}

Among the northeast release points, larvae released from Points 13 (Noku 210), 4 (Miike Island), and 7 (Takehaze) reached habitable areas in the greatest numbers. These results are related to bathymetric features, in particular, shallow areas around these points. Most of the larvae released from these three points were able to reach habitable areas because the surrounding bathymetry affected the direction of tidal currents. Moreover, [25] analyzed settlement of pen shell larvae in the Ariake Sea and found that most larvae settled in elevated, sloped areas. Therefore, larvae from these release points not only reached habitable areas but had a strong potential for settlement of the larvae. Therefore, these three points may be effective areas in which to transplant pen shell as source areas for pen shell larvae.

Most of the habitable areas for pen shells are located in the eastern bay (Fig. 4). Because there is anticlockwise tidal residual flow in the inner bay of the Ariake Sea, larvae released from the northwest area were not able to reach habitable areas. According to [24], the median grain size diameter that pen shells prefer is $>62.5 \mu \mathrm{m}$. However, the bottom of the seabed in the northwest area is composed of mud. In addition, because of environmental changes in the Ariake Sea, grain size is decreasing in this area. Reference [8] conducted a seabed survey with 91 stations in the Ariake Sea and compared the results to those of a survey conducted in 1967. They found that in 2003, grain size had decreased and that the median diameter was $<2.0 \mu \mathrm{m}$ in the northwest area. Reference [26] also conducted a survey of the seabed in the Ariake Sea, reporting that the seabed median diameter was $<7.8 \mu \mathrm{m}$ in the northwest area. Furthermore, anoxic water masses frequently form in the northwest area [27]. Reference [28] reported that in severe hypoxia, pen shells decrease ciliary movement and die of suffocation. These results suggest that the northwest area is currently an inappropriate spawning ground for pen shells and that this area has low potential for recovery. Therefore, Points 1 (Okigamise) and 2 (Tara offshore) are not considered appropriate candidates for transplanting pen shell nor seabed restoration.

Due to the anticlockwise residual flow in the Ariake Sea, most of the larvae released from Isahaya Bay flowed out of the Ariake Sea. Thus, this area also seems inappropriate for restoration of the seabed as a source of larvae. Nevertheless, although the number of larvae that reached habitable areas within the bay from this area was small, the number of larvae that reached this area from other areas was large. Due to the anticlockwise residual flow in the Ariake Sea, most of the 
larvae released from other points ultimately arrived in Isahaya Bay. Furthermore, this area once had reknowned fisheries for pen shells. Thus, this area may not be a larval release area but may be a good settling and nursery area. Therefore, recovery of pen shell resources would be expected after seabed restoration in this area.

\section{CONCLUSIONS}

In this manuscript, we propose locations for effective transplant of pen shell and seabed restoration for recovery of production of pen shells in the Ariake Sea based on the results of a larvae tracking model. A two-dimensional depth-averaged model was developed to reproduce tidal currents in the Ariake Sea. A wet-and-dry scheme was then incorporated into the model to reproduce the appearance of tide flats. The model showed high accuracy in predicting tidal currents and the emergence of tide flats. Using a larval transport model, distribution and settlement of pen shell larvae were then predicted. To investigate potentially effective areas for transplanting pen shell and seabed restoration for recovery of pen shell resources, 14 points were selected as release points for pen shell larvae. The number of larvae that were able to reach habitable areas for pen shells (depth: $2<h<20 \mathrm{~m}$; median grain size diameter: $>62.5 \mu \mathrm{m}$ ) was calculated for each point. The larvae from each release point were transported differently because of the anticlockwise residual tidal flow in the Ariake Sea. Larvae released from the northeast area spread out over the entire bay. Those released from the northwest area settled in the west area, which is inhospitable to pen shell larvae, and those released from Isahaya Bay mainly flowed out of the mouth of the Ariake Sea.

Based on the results of the simulations, larvae released from Point 13 (Noku 210) reached habitable areas in the greatest number, suggesting that there is high potential for survival of larvae released from this point. In addition, Isahaya Bay is the area larvae most frequently reached because of the tidal flow direction in the Ariake Sea. In conclusion, then, we suggest that transplant pen shell in Point 13 and seabed restoration in Isahaya Bay are the most effective approach to recovering pen shell production in the Ariake Sea.

\section{ACKNOWLEDGMENT}

The authors gratefully acknowledge the Ariake Sea Laboratory of the Fukuoka Prefectural Fisheries and Marine Technology Research Center and the Saga Prefectural Ariake Fisheries Research and Development Center for data on the Ariake Sea.

\section{REFERENCES}

[1] H. Koga and Y. Yamashita, "Studies on Atrina sp. in Ariake sea - IV experiment on collecting seedlings of Atrina sp. in natural water (1)," Bulletin of Saga Prefectural Ariake Fisheries Experimental Station, vol 10, pp. 1-8, Apr. 1986.

[2] T. Hamada, Y. Hayami, K. Yamamoto, K. Ohgushi, K. Yoshino, R. Hirakawa, and Y. Yamada, "Serious hypoxia in the head of the Ariake Sea in summer, 2006," Oceanography Society of Japan, vol. 17, no. 5, pp. 371-377, Sep. 2008.

[3] Y. Kajiwara, T. Tomita, T. Nakano, and M. Ishobe, "Occurrence of hypoxic water in the inner area of Ariake Bay in the summer of 2002,"
Journal of Hydraulic, Coastal and Environmental Engineering, vol. 747, no. II-65, pp. 187-196, Nov. 2003.

[4] H. Tsutsumi, E. Okamura, M. Ogawa, T. Takahashi, H. Yamaguchi, S. Montani, N. Kohashi, T. Adachi, and T. Komatsu, "Studies of the cross section of water in the innermost areas of Ariake Bay with the recent occurrence of hypoxic water and red tide," Oceanography in Japan, vol. 12, no. 3, pp. 291-305, May 2003.

[5] I. Kawahara and S. Ito, "Mortality of pen-shells, Atrina pectinata in northeast part fishery of Ariake Sound in summer, 2000 and 2001 - I. occurrence of mortality," Bulletin of Saga Prefectural Ariake Fisheries Experimental Station, vol. 21, pp. 7-13, July 2003.

[6] I. Kawahara, T. Yamaguchi, H. Ohkuma, and S. Ito, "Larval rearing and metamorphosis of the pen-shell, Atrina pectinata in Ariake sound," Bulletin of Saga Prefectural Ariake Fisheries Experimental Station, vol. 22, pp. 41-46, Nov. 2004.

[7] T. Yurimoto, K. Tanaka, N. Nasu, and K. Matsuoka, "Influence of resuspended sediments and their surface accumulation on a pen shell Atrina pectinata in Ariake Bay, west Japan," The Aquaculture, vol. 56, no. 3, pp. 335-342, Sep. 2008.

[8] H. Kondo, M. Azuma, and N. Hideyuki, "Grain size distribution and content of carbon, nitrogen of bottom sediment from the Ariake Bay," Bulletin of the Faculty of Education, Nagasaki University, Natural Science, vol. 68, pp. 1-14, Mar. 2003.

[9] D. F. Johnson and K. H. Hess, "Numerical simulations of blue crab larval dispersal and recruitment," Bull. Mar. Sci., vol. 46, no. 1, pp. 195-213, Jan. 1990.

[10] A. Peliz, P. Marchesiello, J. Dubert, M. Marta-Alemedia, C. Roy, and H. Queiroga, "A study of crab larvae dispersal on the Western Iberian Shelf: physical processes," J. Mar. Sys., vol. 68, pp. 215-236, Nov. 2007.

[11] Y. Thomas, L. R. Gendre, P. Garen, F. Dumas, and S. Andrefouet, "Bivalve larvae transport and connectivity within the Ahe atoll lagoon (Tuamotu Archipelago), with application to pearl oyster aquaculture management," Mar. Poll. Bull., vol. 65, pp. 441-452, Jan. 2012.

[12] B. S. Hu and S. C. Kot, "Numerical model of tides in Pearl River estuary with moving boundary," J. Hydraul. Eng., vol. 123, pp. 21-29, Jan. 1997.

[13] J. Smagorinsky, "General circulation experiments with the primitive equations," Mon. Weather Rev., vol. 91, pp. 99-164, Mar. 1963.

[14] H. Yagi, O. Ishida, A. Takahashi, K. Nadaoka, J. Tamura, and M. Kotani, "Fluid resistance of larvae culture facility and its influence on tidal currents and SOM transport in Ariake Sea," in Proc. Coastal Engineering, JSCE, vol. 51, no. 2, pp. 1026-1030, 2004.

[15] Y. Uchiyama, "Wetting and drying scheme based on a modified logarithmic law for three-dimensional terrain-following coastal ocean models," in Proc. Coastal Engineering, JSCE, vol. 51, no. 1, pp. 351-355, 2004.

[16] S. Ito, "The status and recovery of marine resources in the Ariake sound," Bulletin of Saga Prefectural Ariake Fisheries Experimental Station, vol. 22, pp. 69-80, Nov. 2004.

[17] I. Kawahara, S. Ito, Y. Chikushi, N. Aishima, and H. Kitamura, "Mortality of pen-shells, Atrina pectinata in northeast part fishery of Ariake Sound - II," Bulletin of Saga Prefectural Ariake Fisheries Experimental Station, vol. 22, pp. 17-23, Nov. 2004.

[18] M. D. Graaf, Z. Jager, C. B. Vreugdenhil, and M. Elorche, "Numerical simulations of tidally cued vertical migrations of flatfish larvae in the North Sea," Estuary Coastal Shelf Sci., vol. 59, pp. 295-305, 2004.

[19] H. Nakata, M. Fujiwara, Y. Suenaga, T. Nagasawa, and T. Fujii, "Effect of wind blows on the transport and settlement of brown sole (Pleuronectes herzenteini) larvae in a shelf region of the Sea of Japan: numerical experiments with an Euler-Lagrangian model," J. Sea Res., vol. 44, pp. 91-100, Oct. 2000.

[20] T. Yanagi, H. Tsukamoto, H. Inoue, and T. Okaichi, "Numerical simulation of drift cards dispersion," La. Mer., vol. 21, pp. 218-224, 1983.

[21] J. Sagara, "On the utilization of tideland by means of shell-fish propagation,” Fisheries Engineering, vol. 13, no. 2, pp. 17-20, 1977.

[22] T. Akimoto, N. Aishima, M. Hayashi, and Y. Watanabe, "Relationship between the area of habitat Atrina pectinata and environment in the Ariake Sea," Bulletin of Fukuoka Fisheries Marine Technology Research Center, vol. 2, pp. 79-83, Mar. 1994.

[23] H. Koga, "The properties of bottom mud and benthos in the north western part of Ariake Sea," Bulletin of Saga Prefectural Ariake Fisheries Experimental Station, vol. 13, pp. 57-79, Mar. 1991.

[24] M. Tanaka, S. Inagaki, and K. Yamaki, "Numerical simulation of tide and three dimensional flow in Ariake Bay," in Proc. Coastal Engineering, JSCE, vol. 49, no. 1, pp. 406-410, 2002. 
[25] T. Akimoto, M. Hayashi, N. Aishima, J. Sano, K. Futashima, and Y. Watanabe, "Setting and growth of pen-shell (Atrina pectinata) on the artificial sandbank fishing ground," Bulletin of Fukuoka Fisheries Marine Technology Research Center, vol. 4, pp. 45-52, Mar. 1995.

[26] H. Yokoyama and Y. Ishii, "Zoning of the inner part of Ariake Sound based on principal component analysis of sediment factors," Nippon Suisan Gakkaishi, vol. 75, no. 4, pp. 674-683, July 2009.

[27] Nakayama, S. Saeki, T. Shibayama, and M. Isobe, "A field survey on the occurrence of an anoxic seawater in the northern west part of Sea of Ariake," in Proc. Coastal Engineering, JSCE, vol. 50, no. 2, pp. 976-980, 2003.

[28] K. Yamamoto, T. Handa, and A. Nishioka, "Effect of hypoxia on ventilation in the pen shell Atrina (Servatrina) lishkeana," Aquaculture Science, vol. 54, no. 3, pp. 319-323, Sep. 2006.

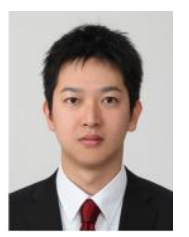

T. Tabata was born in Kagoshima, Japan, in 1988. He received the B.E. and M.S. degrees in agriculture from the Kyushu University, Fukuoka, Japan, in 2010 and 2012, respectively.

He joined Graduate School of Bioresource and Bioenvironmental Sciences, Kyushu University, Fukuoka, Japan, as a research fellowship for Young Scientists of Japan Society for the Promotion of Science (DC1) in 2012. His current research interests include agriculture engineering, water environmental engineering and environmental hydraulics.

Mr. Tabata is a member of The Japanese Society of Irrigation, Drainage and Rural Engineering.

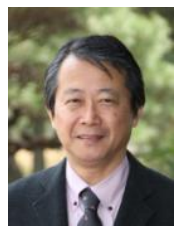

K. Hiramatsu was born in Fukuoka, Japan, in 1958. He received the B.E., M.E. and Ph.D. degrees in agriculture from Kyushu University, Fukuoka, Japan, in 1981, 1983 and 1986, respectively.

$\mathrm{He}$ is currently a professor in the Faculty of Agriculture, Kyushu University, Fukuoka, Japan, since 2005. From 2001 to 2005, he was an associate professor in the Faculty of Agriculture, Kyushu University, where he was an assistant professor since 1987. His main areas of research interest are environmental hydraulics and environmental hydrology.

Dr. Hiramatsu is the dean of the Faculty of Agriculture, Kyushu University and a vice president of JSIDRE (the Japanese Society of Irrigation, Drainage and Rural Engineering), and a member of JRCSA (the Japan Rainwater Catchment Systems Association), the International Association of Hydrological Sciences, and the International Water Association.

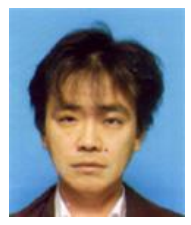

M. Harada was born in Fukuoka, Japan in 1972. He received the B.E., M.S., and Ph.D. degrees in agriculture from Kyushu University, Fukuoka, Japan, in 1994, 1996, and 1999 , respectively.

$\mathrm{He}$ joined the Faculty of Agriculture, Tottori University, Tottori, Japan, as an assistant professor in 2000. Since 2005, he has been with the Faculty of Agriculture, Kyushu University, Fukuoka, Japan, where he is currently an associate professor.

Dr. Harada is a member of JSIDRE (The Japanese Society of Irrigation, Drainage and Rural Engineering) and JRCSA (Japan Rainwater Catchment Systems Association) 